\title{
Em busca do rádio de autor: apontamentos para uma rediscussão crítica da história do rádio no país ${ }^{1}$
}

//I/I/I/I/// : Eduardo Vicente ${ }^{2}$

1. Este artigo é a versão revista de um trabalho apresentado no GP Rádio e Mídia Sonora do XXXIV Congresso Brasileiro de Ciências da Comunicação, ocorrido no Recife (2011).

2. Doutor em Comunicação e professor do Curso Superior do Audiovisual e do Programa de Pós-Graduação em Meios e Processos Audiovisuais da Escola de Comunicações e Artes da Universidade de São Paulo. E-mail: eduvicente@usp.br 


\section{Resumo}

Este texto se propõe a oferecer alguns apontamentos para uma discussão crítica da história do rádio no país que valorize sua dimensão mais autoral. Ele parte do entendimento de que a visão hegemônica que se estabeleceu acerca da história do veículo no Brasil acaba por dificultar uma discussão mais abrangente de seus autores, de seu repertório e das suas potencialidades de desenvolvimento, diante do leque de alternativas de produção, difusão e uso social oferecido pelas novas tecnologias digitais. Dentro desse quadro, é desenvolvida uma discussão crítica do relato sobre a história no Brasil oferecido por Gisela Ortriwano em seu livro A Informação no rádio, publicado em 1985.

\section{Palavras-chave}

teoria do rádio, história do rádio, linguagem radiofônica

\section{Abstract}

The present article brings up some points that can lead to a critical review of the Brazilian radio history - one that values the authors' dimension. The established hegemonic outline on the media history avoids a broad discussion that considers the radio authors, its repertory and the development potentials, which may be found in the broadening scenario of alternative production, broadcast and social uses offered by the digital technologies. Thus, this article discusses the report of the radio's history in Brazil provided by Gisela Ortriwano's book, A informação no rádio (Information on radio), published in 1985 .

\section{Key-words}

radio theory, history of radio, radio language 
A massa ainda comerá o biscoito fino que eu fabrico.

Oswald de Andrade

Este texto se propõe a oferecer elementos para o que considero como uma necessária revisão crítica e uma ampliação do debate em torno da história do rádio no país, no sentido da valorização de sua dimensão mais propriamente autoral e artística. Essa questão, no contexto de minhas pesquisas sobre o rádio, liga-se ao conceito de "rádio possível", que comecei a desenvolver em 2006 como uma forma de afirmação da possibilidade de existência de um rádio mais experimental e autoral, que possa ser compreendido como um "meio de expressão" e não "unicamente como um meio de difusão de informação (verbal, musical) a públicos distantes e heterogêneos" (BALSEBRE, 1994, p. 14). A proposição desse conceito parte da premissa de que, diante das novas alternativas abertas para a produção e para a veiculação radiofônica a partir dos diferentes usos sociais possibilitados pelas tecnologias digitais, faz-se necessária uma discussão crítica dos referenciais teóricos, da estética e da história do veículo no país, que possa nos oferecer uma visão mais "aberta" do rádio, apta a explorar as múltiplas possibilidades desse seu novo momento. Por isso, entendo a ideia de "rádio possível" como uma estratégia de abordagem do passado e do presente do rádio, no sentido de prospectar suas dimensões autorais, experimentais e expressivas para uma exploração mais radical de suas novas possibilidades de utilização. 
É à "abordagem do passado" que irei dedicar o presente texto. Tentarei demonstrar que a recuperação de uma perspectiva mais crítica sobre as potencialidades de uso social do rádio no Brasil deve necessariamente passar por uma "reabertura" da discussão de sua história, que nos possibilite uma visão menos naturalizada da trajetória percorrida até o momento atual e nos ofereça uma compreensão menos limitadora de suas características e possibilidades de uso. Com esse objetivo, irei desenvolver uma discussão crítica sobre a visão da história do rádio no país apresentada por Gisela Ortriwano (1985) para, em seguida, apresentar alguns elementos que me parecem fundamentais para uma visão histórica do veículo que considere de forma mais consistente sua dimensão autoral. A discussão do texto de Ortriwano advém, evidentemente, do fato de ele ter se tornado talvez a mais importante referência para os estudos sobre o veículo no país. Embora o livro apresente um relato bastante resumido sobre a história do rádio no Brasil, ele traz uma proposta de periodização e uma visão sobre o desenvolvimento do veículo que, a meu ver, acabaram por se consolidar como relatos hegemônicos nesse campo - por isso, considero fundamental a realização de um esforço no sentido de sua revisão crítica e superação.

Mas quero deixar claro que não considero a obra de Ortriwano como conservadora ou acrítica. Na verdade, a autora empreendeu um estudo ousado e abrangente sobre o rádio do Brasil, buscando uma chave para a compreensão da sua história, linguagem e características. Entendo, no entanto, que o foco da autora foi a questão da informação no rádio e que ela não tinha a pretensão de escrever uma "história do rádio" - que, quase três décadas depois, ainda iria se manter como nosso texto canônico sobre o tema.

Considero que há pelo menos dois pontos que tornam esse olhar sobre o passado importante para o futuro do rádio. Em primeiro lugar, o que Miège (2009) denomina como uma dupla mediação, ou seja, uma dimensão sociotécnica que media nossa relação com as novas tecnologias de comunicação. Nesse contexto, se por um lado as tecnologias acabam determinando novas práticas de produção pelas suas características, por outro, a relação com os novos meios se dá menos por rupturas do que pela "continuidade de processos complexos e engajados há muito tempo" (2009, p. 18). Assim, as práticas historicamente estabelecidas no âmbito da produção radiofônica acabam assumindo um importante papel mes- 
3. Entendo as dificuldades em torno da conceituação de gêneros e formatos no rádio, mas não pretendo desenvolver aqui esta discussão. De qualquer modo, utilizo o termo "radioarte" a partir da conceituação oferecida por Lídia Camacho (2007). mo num contexto de grandes mudanças tecnológicas, situação que torna fundamental um questionamento sobre o processo histórico que levou à sua consolidação. Desnaturalizar o desenvolvimento histórico dessas práticas e compreender que outras possibilidades de produção já foram exploradas no Brasil pode nos ajudar a assumir uma visão mais abrangente sobre as potencialidades do rádio e de sua linguagem, capaz de iluminar os caminhos possíveis para o veículo em seu contexto atual.

Em segundo lugar, essa revisão histórica possibilita uma compreensão das potencialidades expressivas, experimentais e artísticas do rádio, que se manifestam normalmente através de gêneros como o radiodrama e a radioarte ${ }^{3}$, como mais do que meramente "elitistas" ou, pior ainda, como reminiscências fossilizadas de sua infância. Essa visão limitadora pode prejudicar um uso mais radical e inovador da linguagem de rádio em espaços de difusão alternativos como projetos sociais, educacionais ou rádios comunitárias - que se veriam, desse modo, condenados a reproduzir os modelos tradicionais de difusão assumidos pelas grandes emissoras, lançando mão de uma linguagem padronizada, empobrecida, mas, dentro de uma visão conservadora do veículo, "compreensível para as massas".

Gostaria agora de me dedicar à discussão do texto de Ortriwano, apontando, nesse processo, para algumas questões que me parecem pertinentes no sentido do estabelecimento de uma perspectiva mais ampla para a discussão da história do rádio no Brasil.

\section{A história do rádio na obra de Gisela Ortriwano}

Professora do Departamento de Jornalismo da ECA (Escola de Comunicações e Artes) da Universidade de São Paulo, Gisela Ortriwano publicou A informação no rádio: os grupos de poder e a determinação dos conteúdos em 1985. A obra se propunha a oferecer uma visão abrangente sobre o veículo no país, apresentando sua história, modelo de desenvolvimento, organização econômica, legislação, características gerais e uso jornalístico. A qualidade e o caráter abrangente do texto acabaram por transformá-lo em uma obra de referência para cursos de graduação na área de comunicação, especialmente jornalismo e radialismo. Mas entendo que o trabalho não possuía a pretensão de se tornar "a” história do rádio no Brasil, 
como acabou por ocorrer. O relato histórico, inclusive, é bastante sucinto, ocupando apenas 16 páginas (p. 13 a 28) do primeiro capítulo do livro. Por isso, como já foi apontado aqui, considero a necessidade de estabelecermos uma visão mais crítica e atualizada desse relato, revendo especialmente as conclusões apontadas pela autora. Com esse objetivo, gostaria primeiramente de apresentar um breve resumo da história do rádio oferecida por Ortriwano. A implantação do veículo no país, a partir da iniciativa de Edgar Roquette-Pinto e Henrique Morize, em 1923, é vista - apesar de suas finalidades educativas - dentro de uma perspectiva eminentemente elitista:

ouvia-se ópera com discos emprestados pelos próprios ouvintes, recitais de poesia, concertos, palestras culturais etc., sempre uma programação muito 'seleta', apesar de Roquette-Pinto estar convencido, desde o início, de que o rádio se transformaria num meio de comunicação de massa (ORTRIWANO, 1985, p. 14).

Como consequência disso, "a cultura popular não tinha acesso ao rádio” (p. 14). Mas, a partir da ascensão de Getúlio Vargas, o rádio "sofre transformação radical". A publicidade é regulamentada, e "a introdução de mensagens comerciais transfigura imediatamente o rádio: o que era 'erudito', 'educativo', 'cultural' passa a transformar-se em "popular', voltado ao lazer e à diversão" (p. 15). Nesse momento, as emissoras se organizam, se multiplicam, e "o rádio brasileiro vai encontrando seu caminho, definindo sua linha de atuação e assumindo um papel cada vez mais importante na vida política e econômica do país" (p. 17).

Assim, para a autora,

o decênio de zo foi importante para que o rádio se definisse em seus caminhos e encontrasse seu rumo na fase seguinte, acompanhando e auxiliando o desenvolvimento nacional como um todo (...). E assim preparado, o rádio entra nos anos 40, a chamada "época de ouro do rádio brasileiro ( $p .19$ ).

Na opinião de Ortriwano, essa

"época de ouro" do rádio termina, coincidentemente, com o surgimento no Brasil de um novo meio: a televisão. Quando surge, ela 
vai buscar no rádio seus primeiros profissionais, imita seus quadros e carrega com ela a publicidade. Para enfrentar a concorrência com a televisão o rádio precisava procurar uma nova linguagem, mais econômica. Aos poucos, ele vai encontrando novos rumos (p. 21).

Esses "novos rumos", para a autora, estavam no radiojornalismo (tema que ela discute com mais profundidade), nos serviços de utilidade pública, na veiculação musical com as emissoras de FM e na especialização (p. 22-24). A conclusão de Ortriwano é a de que, “pelo breve histórico do desenvolvimento do rádio no Brasil, podemos verificar que o processo segue paralelo ao do próprio desenvolvimento do país" (p. 28).

Apresentado o relato, o primeiro de seus aspectos que gostaria discutir é o da afirmação da finalidade comercial como sinônimo da popularização ou democratização do veículo. Embora a autora aponte em seu livro também para o problema da sobreposição dos interesses econômicos às necessidades da população no processo de expansão do rádio (p. 28), essa crítica não parece contaminar o seu relato histórico. O que acaba destacando-se é a utilização dos termos "erudito", "educativo" e "cultural" como sinônimos de uma visão "elitista” do rádio e, portanto, oposta ao "popular".

Várias questões podem ser levantadas a partir dessa oposição. Em primeiro lugar, a definição como "elitista" de um rádio que não dedique sua programação predominantemente ao "lazer e à diversão". Como sabemos, se o Brasil adotou um modelo comercial de rádio inspirado no norte-americano, na Europa e no Japão, tornou-se predominante um modelo de rádio público ou estatal, com ênfase no uso educativo e cultural do veículo. Entendo que seria despropositado considerar que esses modelos de radiodifusão, que geraram emissoras como BBC (Reino Unido), Deutsche Welle (Alemanha), RFI (França) e NHK (Japão), entre outras, não sejam também populares em alguma medida. Além disso, sua afirmação como "popular" empresta um considerável nível de legitimidade ao modelo comercial de rádio adotado no país e às emissoras que se consolidaram dentro dele, o que dificulta o estabelecimento de uma visão crítica sobre os rumos assumidos pelo veículo em seu desenvolvimento no Brasil.

Em segundo lugar, ao assumirmos a oposição proposta pela autora, acabamos por desqualificar qualquer pretensão educativa, 
cultural, artística ou experimental que o rádio tenha, já que podem ser consideradas como elitistas e, portanto, opostas ao caráter popular do veículo. Nesses termos, voltado exclusivamente ao entretenimento popular, o rádio nega completamente o seu potencial para a expressão individual e para a experimentação estética, ou seja, para o desenvolvimento do que poderíamos denominar como uma arte radiofônica. Vale lembrar que se isso não ocorreu na Europa, com seus modelos público e estatal, em que importantes autores, como Bertold Brecht, Walter Benjamin, Friedrich Dürrenmatt, Harold Pinter e Samuel Beckett, entre outros, dedicaram diversas de suas obras ao veículo. E também não ocorreu totalmente nos EUA, mesmo dentro do modelo comercial, como a trajetória radiofônica de Orson Welles, por exemplo, parece demonstrar.

Mas cabe aqui perguntar se isso também não ocorreu no Brasil. $\mathrm{E}$ a resposta a essa questão pode nos levar à conclusão de que a oposição simples entre elitista e popular talvez esteja impedindo um olhar sobre o rádio no Brasil que expresse a complexidade de sua produção, muito mais diversificada e sofisticada do que o mero direcionamento ao "lazer e à diversão" faria supor. Pois definir o rádio brasileiro no período de sua "época de ouro" como "popular", nos termos propostos por Ortriwano, talvez ajude a ocultar o fato de que projetos bastante sofisticados e ambiciosos foram realizados no período. No campo da música popular, por exemplo, podemos citar pelo menos dois casos emblemáticos. O primeiro é o de Radamés Gnattali e de seu trabalho à frente da Orquestra Brasileira da Rádio Nacional, especialmente no programa Um milhão de melodias, em que eram criados sofisticados arranjos orquestrais para composições populares nacionais e internacionais (BARBOSA \& DEVOS, 1984; SAROLDI \& MOREIRA, 1984). Como se sabe, Radamés e sua música acabaram por se tornar importantes influências para alguns dos principais precursores da Bossa Nova ${ }^{4}$. O segundo caso é o de Almirante, que, embora fosse um cantor e compositor popular, demonstrou evidentes preocupações didáticas em muitos dos programas que criou para a Rádio Nacional - que também por essa razão basearam-se num extenso trabalho de pesquisa musical e folclórica (CABRAL, 1990).

No campo da ficção radiofônica, também é possível enumerar trabalhos aos quais não faltou uma certa dose de experimentação, de marca autoral e de engajamento político. A análise de Lia Calabre
4. O que, em um certo sentido, pode-se inferir dos discursos já bastante antigos e caros à filosofia ocidental, como o mito da caverna platônico. 
5. Ortiz considera que a associação do popular "ao que é mais consumido" se dará no Brasil apenas a partir dos anos 6o, quando ele considera que teremos a efetiva consolidação de um mercado de bens culturais no país (ORTIZ, 1988, p. 164).
(2006) sobre as radionovelas da Nacional mostra que, após a queda de Vargas, em 1945, algumas das produções foram bem além do melodrama tradicional ou da reprodução da moral conservadora, incorporando questões trabalhistas e mesmo confrontos de classe. Já nos trabalhos que autores como Túlio de Lemos e Dias Gomes produziram para o rádio paulista, por exemplo, vemos uma forte marca autoral e uma evidente preocupação com a explicitação da luta de classes e da crítica social para um público amplo (GUERRINI JR., 2005; VICENTE, 2011). Assim, entendo que o rádio no Brasil, mesmo que desenvolvido dentro de um modelo comercial, teve sua marca autoral e também pode ser pensado a partir da perspectiva desses autores e de suas preocupações estéticas e políticas.

E isso nos leva a uma outra questão implícita na oposição entre elitista e popular proposta pela autora que é a da definição de “popular" como sinônimo de comercial. Para Renato Ortiz, "até recentemente existiam entre nós duas grandes tradições que procuravam pensar a problemática do nacional-popular” (1988, p. 160). Dentro de uma delas, "popular significa tradicional, e se identifica com as manifestações culturais das classes populares, que devem ser preservadas em museus, livros etc." (p. 160). Trata-se, no caso, de uma visão conservadora, que nega atualidade histórica à cultura popular. Já dentro de uma perspectiva de mudança social, popular apresenta-se como uma opção política, como um projeto de transformação social. Nesses termos, entendo que poderíamos ver as obras de autores engajados como os já citados Dias Gomes e Túlio de Lemos ou, ainda, o trabalho de Oswaldo Molles (especialmente em História das malocas) como "populares", dentro desse sentido político-progressista. Assim, creio que deveríamos evitar definir tais artistas como elitistas ou caracterizar o "popular" do período como necessariamente "comercial" 5

Mas, mesmo deixando a esfera dos autores e concentrando-nos na questão das emissoras, acho possível constatar que, ao menos entre as empresas de São Paulo, nem todas seguiram no período um modelo que possa ser considerado como "popular", no sentido sugerido por Ortriwano. É o caso da Rádio Gazeta de São Paulo, inaugurada em 1943 com uma programação fortemente baseada na música erudita, especialmente na ópera (GUERRINI JR., 2009).

Finalmente, e sem ter condições de me estender no momento sobre essa questão, gostaria de assinalar que também me parece pro- 
blemático definir o projeto de Roquette-Pinto como decididamente elitista e distante do público. Por um lado, como demonstra o trabalho apresentado por Michele Vieira no Congresso da Intercom de 2010, a análise das cartas enviadas pelos ouvintes para a Rádio Sociedade do Rio de Janeiro, ainda nos anos 20, parece demonstrar que pessoas de diferentes camadas sociais aparentemente sentiam identidade suficiente com a emissora e com o próprio Roquette para enviar críticas e sugestões à programação musical da rádio (VIEIRA, 2010). Por outro, entendo que seria importante uma discussão mais aprofundada sobre esse momento de consolidação do rádio no país, na busca de uma melhor compreensão do processo de definição do seu modelo de desenvolvimento. Afinal, a escolha de um formato comercial de rádio em 1932 parece contraditória, se considerarmos o grande interesse do Governo Vargas pelo uso do veículo como instrumento de propaganda política. Escrevendo para a Revista Cultura Política, editada pelo DIP (Departamento de Imprensa e Propaganda) entre os anos de 1941 e 1945, Álvaro Salgado, um dos ideólogos do regime para o setor radiofônico, oferece-nos o que parece ser uma posição oficial do governo sobre essa questão:

é cedo para a radiodifusão exclusivamente oficial. O que nos convém, o mais eficiente no momento, é a rádio controlada ao lado de algumas estações oficiais. Obter-se-á, assim, um equilíbrio, a fim de que os programas não sejam, inteiramente, conformes com o gosto do povo, mas de acordo com as necessidades do ouvinte (SALGADO, 1941, p. 40).

Assim, diante da aparente impossibilidade do governo, naquele momento inicial e ainda turbulento do período varguista, em criar um modelo estatal de rádio, a solução encontrada parece ter sido a de uma "rádio controlada", em que a preocupação central talvez não fossem exatamente as necessidades do ouvinte, mas as do próprio regime. Nesse sentido, seria importante olhar o período de consolidação e auge do rádio, entre as décadas de 30 e 50, também sob o viés da presença e da intencionalidade do Estado em relação ao setor, algo que não ocorre com o texto de Ortriwano.

Outra questão que me parece problemática no texto da autora é a de que ele parece assumir a ideia de uma naturalização da trajetória histórica do rádio no país, afirmada através de expressões como “encontro de um rumo" e "uma trajetória que segue paralela à do 
6. A novela superou a marca dos 15.700 episódios entre a TV e o rádio; ver <http://www.cbs.com/daytime/ guiding_light/about/>, acessado em 28 de setembro de 2011 . desenvolvimento do país" etc. Isso sugere a imagem de um destino inequívoco e, portanto, a impossibilidade de alternativas para o desenvolvimento do veículo. Portanto, dentro dessa trajetória naturalizada, ficam interditadas uma visão crítica das escolhas históricas e, mais grave ainda, a discussão sobre outros caminhos possíveis para o rádio. Ou seja, o rádio é o que é, é o que pode ser.

Tomemos a questão do "novo rumo" assumido pelo veículo a partir da chegada da TV, por exemplo. Quando visto, como é o caso aqui, enquanto evolução lógica da trajetória do veículo, busca por uma "linguagem mais econômica", ele dificulta a discussão de fenômenos como a concentração econômica ou o empobrecimento da programação. Por essa via, temos aqui a ruptura com a tradição desenvolvida na época de ouro - especialmente através dos programas de auditório, da ficção, da veiculação de música ao vivo etc. - lida como evolução histórica do rádio, superação de uma programação obsoleta. Porém, se nos reportarmos à história do rádio nos EUA, onde o veículo também adotou um modelo comercial para o seu desenvolvimento, veremos que a opção pela veiculação musical, pelo jornalismo e pela utilidade pública ocorreu, na verdade, no momento inicial do desenvolvimento do veículo, ainda nos anos 20, de modo que em 1927 os EUA já contavam com duas grandes redes de emissoras, CBS e NBC - operando exclusivamente ao vivo e com uma programação baseada nesse tripé. No final da década seguinte, com a superação da crise de 1929, o modelo seria substituído pelo da "época de ouro", em que as radionovelas e os programas de auditório seriam o grande destaque, com o retorno a uma programação mais econômica acontecendo, como aqui, apenas após a chegada da TV.

$\mathrm{E}$, assim como no Brasil, muitos dos programas do rádio migraram para a TV, o que parece demonstrar que eles acabaram mantendo sua atualidade e pertinência para o público consumidor. A radionovela Guiding light, criada por Irna Philips em 1937 para a rede norte-americana CBS, é um caso exemplar dessa transição. Com capítulos diários de 15 minutos, ela passou a ser veiculada simultaneamente na TV e no rádio em 1952, deixando este último apenas quatro anos depois e mantendo-se na programação da rede de TV até o final de $2009^{6}$. Já numa emissora pública como a BBC, do Reino Unido, há casos em que essa transição nem mesmo ocorreu. A radionovela The archers, por exemplo, criada em 1951, mantém-se 
na programação da BBC Radio 4 até o presente ${ }^{7}$. Nessa emissora, o rádio não apenas manteve formatos ficcionais como eles ocasionalmente funcionaram como fonte de inspiração para outras mídias. Isso ocorreu, por exemplo com a série radiofônica Hitchhiker's guide to the galaxy (O guia do mochileiro das galáxias) que, criada por Douglas Adams em 1978, transformou-se posteriormente numa série de livros, numa série televisiva, num longa-metragem e em diversos videogames.

Além disso, um projeto como o da Rádio Eldorado de São Paulo, fundada em 1958 com auditório próprio e uma programação musical voltada de forma praticamente exclusiva para a música erudita, parece demonstrar que o processo de adaptação do rádio aos cenários dos anos 6o, com a presença da TV e um acelerado desenvolvimento da indústria de bens simbólicos no país (ORTIZ, 1988), tende a ser mais complexo do que a mera afirmação do "novo rumo" parece indicar, demonstrando que, em algum nível, um projeto de estratificação também se manifestava dentro da produção radiofônica em AM (as emissoras em FM iriam se popularizar apenas a partir dos anos 70).

\section{A questão do repertório}

Mas, além da revisão crítica aqui proposta, entendo que outras questões importantes teriam de ser enfrentadas no sentido da construção de uma visão mais abrangente da história do rádio no país e igualmente vinculadas à sua dimensão mais artística.

Em primeiro lugar, um estudo mais amplo e aprofundado de obras e realizadores de destaque, que nos permitam um olhar sobre o rádio também pelo viés de sua produção. Essa proposta se baseia na crítica feita por Arlindo Machado aos estudos de TV, na qual ele destaca que:

é preciso (também) pensar a televisão como o conjunto dos trabalhos audiovisuais (variados, desiguais, contraditórios) que a constituem, assim como cinema é o conjunto de todos os filmes produzidos e literatura, o conjunto de todas as obras literárias escritas ou oralizadas, mas, sobretudo, daquelas obras que a discussão pública qualificada destacou para fora da massa amorfa da trivialidade (MACHADO, 2000, p. 19).
7. <http://www.bbc.co.uk/radio4/ features/the-archers/>, acessado em 28 de setembro de 2011. 
8. Um trabalho bastante significativo nessa área está sendo realizado por Irineu Guerrini Jr., que analisa a obra de Túlio de Lemos a partir de um projeto individual de pesquisa que desenvolve na Faculdade Cásper Líbero.
Nesse sentido, entendo que, embora diversos estudos sobre o rádio no Brasil estejam ligados a pesquisas sobre emissoras, sobre programas ou sobre o trabalho de profissionais que atuaram no veículo, a questão do repertório como forma de construção de uma tradição estética do rádio dificilmente é buscada ${ }^{8}$. Evidentemente, esse tipo de estudo, no país, também é prejudicado pela enorme carência de acervos de gravações e roteiros. Mas isso, em parte, talvez seja também um sinal da falta de pesquisadores interessados na recuperação e na análise das obras.

\section{Conclusões}

A intenção desse texto foi demonstrar que a recuperação de uma dimensão mais autoral dentro da história do rádio brasileiro enfrenta dificuldades advindas em parte do relato hegemônico que se estabeleceu acerca dessa história, em que, entre outros pontos, o artístico é visto como "elitizado" e oposto a "popular", tomado como sinônimo de democrático. Além disso, uma visão naturalizada do desenvolvimento histórico do rádio no país tende a considerar gêneros mais propriamente artísticos - especialmente o radiodrama - como superados, ligados irremediavelmente ao passado do rádio ou a uma produção marginal e basicamente restrita ao meio acadêmico.

Essa visão nos oferece poucas possibilidades de questionamento dos modelos comerciais de programação atualmente dominantes, dificultando a discussão de modos alternativos de produção, mais adequados aos diferentes usos sociais (e não comerciais) hoje possíveis no âmbito da produção radiofônica. Espero que este trabalho colabore em alguma medida para a ampliação desse debate, auxiliando tanto no estabelecimento de uma visão da importância histórica do veículo também como espaço de expressão pessoal e realização artística quanto numa discussão mais radical das possibilidades de sua linguagem e produção no sentido da ruptura com a lógica da repetição acrítica dos modelos vigentes. 


\section{Referências}

BALSEBRE, A. El lenguaje radiofónico. Madrid: Cátedra, 1994.

BARBOSA, V.; DEVOS, A. M. Radamés Gnattali: o eterno experimentador. Rio de Janeiro: Funarte, 1984.

CABRAL, S. No tempo de almirante. Rio de Janeiro:

Francisco Alves, 1990.

CALABRE, L. Rádio na sintonia do tempo: radionovela e cotidiano (1940-1946). Rio de Janeiro: Casa de Rui Barbosa, 2006.

CAMACHO, L. A elite no ar: óperas, concertos e sinfonias na

Rádio Gazeta. São Paulo: Terceira Margem, 2009. El radioarte: um género sin fronteras.

México D. F.: Trillas, 2007.

GUERRINI Jr., I. "De um sótão no Quartier Latin para uma

kitchinete na Avenida São João: La Boheme e Outras Óperas na Rádio Tupy de São Paulo". Comunicare Revista de Pesquisa da Faculdade Cásper Libero, São Paulo, v. 5. n. 2, p. 67-75, 2005.

MACHADO, A. A televisão levada a sério. São Paulo: Senac, 2000.

MIÈGE, B. A sociedade tecida pela comunicação: técnicas da informação e da comunicação entre inovação técnica e enraizamento social. São Paulo: Paulus, 2009.

ORTIZ, R. A moderna tradição brasileira. São Paulo: Brasiliense, 1988. ORTRIWANO, G. A Informação no rádio: os grupos de poder e a determinação dos conteúdos. São Paulo: Summus, 1985.

SALGADO, A. F. "Radiodifusão, fator social”. Revista Cultura Política. Rio de Janeiro: DIP, ano 1, n. 6, 1941.

SAROLDI, L. C.; MOREIRA, S. V. Rádio Nacional: o Brasil em sintonia. Rio de Janeiro: Funarte, 1984.

VICENTE, E. "Radiodrama em São Paulo: a história de Zé Caolho, de Dias Gomes". In: VIII Encontro Nacional de História da Mídia, 2011.

VIEIRA, M. C. "A preferência dos ouvintes da Rádio Sociedade do Rio de Janeiro: uma disputa de sentidos entre o erudito e o popular". In: XXXIII Congresso Brasileiro de Ciências da Comunicação da Intercom, 2010, Caxias do Sul. 